\title{
A LEGITIMIDADE NA REGULAMENTAÇÃO DO DIREITO À VIDA: TENSÕES ENTRE O LEGISLATIVO E O JUDICIÁRIO NA CONCRETIZAÇÃO DA CONSTITUIÇÃO
}

\author{
LEGITIMACY IN THE REGULATION OF THE RIGHT TO LIFE: TENSIONS \\ BETWEEN THE LEGISLATIVE AND THE JUDICIARY IN THE \\ IMPLEMENTATION OF THE CONSTITUTION
}

\author{
${ }^{1}$ Federico Losurdo \\ ${ }^{2}$ Kennya Regyna Mesquita Passos
}

\section{RESUMO}

O julgamento da ADPF 54 pelo Supremo Tribunal Federal teve como efeito a regulamentação do início da proteção constitucional à vida, silenciada na Constituição Federal de 1988 e na legislação ordinária. Todavia, a tramitação perante o Legislativo de Projeto de Lei prevendo a criminalização da interrupção da gravidez por diagnóstico de anencefalia fetal reacende as tensões acerca dos limites da atuação dos poderes Judiciário e Legislativo na concretização dos direitos fundamentais, as quais serão analisadas no presente trabalho à luz do direito comparado, a fim de compreender como a regulamentação do direito à vida se estabeleceu em outros Estados Democráticos.

Palavras-chave: Direito à vida - Jurisdição Constitucional - Interpretação - Legitimidade Aborto

\begin{abstract}
The trial of ADPF 54 by the Supreme Court had the effect of regulating the beginning of the constitutional protection of life, silenced in the Federal Constitution of 1988 and in the ordinary legislation. However, the presentation of a legislative proposal for criminalizing the termination of pregnancy, due to the diagnosis of fetal anencephaly, provokes rising tensions about the limits of the judicial and legislative powers in the implementation of fundamental rights. In this study, these tensions will be analyzed in the light of comparative law, in order to understand how the regulation of the right to life is disciplined in other democratic States.
\end{abstract}

Keywords: Right to life - Constitutional Jurisdiction - Interpretation - Legitimacy - Abortion

\footnotetext{
${ }^{1}$ Doutor em Filosofia pela Universidade de Urbino, Itália (UNIURB), Urbino, Itália. Professor permanente do Programa de pósgraduação em Direito e Instituições do Sistema de Justiça pela Universidade Federal do Maranhão (UFMA), São Luís, Maranhão, Brasil. Email: federico.losurdo@uniurb.it

${ }^{2}$ Mestranda do Programa de pós-graduação em Direito e Instituições do Sistema de Justiça pela Universidade Federal do Maranhão (UFMA), São Luís, Maranhão, Brasil. Bolsista pela Fundação de Amparo à Pesquisa e ao Desenvolvimento Científico e Tecnológico do Maranhão (FAPEMA), São Luís, Maranhão, Brasil. Email: kennyapassos@ hotmail.com
} 


\section{INTRODUÇÃ̃}

Entre os preceitos fundamentais inseridos no texto constitucional brasileiro está o direito à vida, cuja regulamentação sempre foi um tema controverso no sistema jurídico, tratado de forma incipiente inclusive pelas próprias Constituições. As Cartas políticas de 1824 e 1891 previam o direito à segurança dos indivíduos, mas sem mencionar um direito à vida, ocorrendo o mesmo nos textos de 1934 e 1937, embora já existisse aqui uma vedação à pena de morte.

É a partir da Constituição de 1946 que a "vida" passou a ser expressamente reconhecida como bem jurídico autônomo e portanto direito dos indivíduos, a reclamar proteção do Estado, embora não absoluta diante da previsão da pena de morte, excepcionalmente autorizada nos casos de guerra externa, o que se repetiu nos ordenamentos de 1967 e na sua alteração dada pela "Emenda Constitucional” de 1969.

Na Assembleia Nacional Constituinte de 1988 um forte debate foi travado acerca da definição de um termo inicial para o direito à vida, polarizado em duas tendências: a primeira defendia que o direito à vida estaria assegurado desde a concepção, enquanto a segunda sustentava que direito à vida só seria possível após o nascimento. Todavia prevaleceu o entendimento de que à Constituição não caberia regular a matéria, produzindo uma lacuna acerca da proteção jurídico-constitucional da vida humana intrauterina, que até os dias de hoje não foi devidamente colmatada.

Trata-se de um direito fundamental autônomo e inviolável que impõe ao Estado tanto um viés negativo de não intervenção, quanto uma obrigação positiva de executar medidas fáticas e normativas para a sua proteção (CANOTILHO, 2000), dimensões cuja regulamentação torna-se cada vez mais específica, urgente e problemática, sobretudo em relação à vida embrionária, considerando-se os avanços biotecnológicos que permitem a manipulação de células zigóticas, controle genético e intervenções fetais, provocando indagações interdisciplinares que exigem respostas jurídicas complexas, atravessadas por questões de ordem moral e social (FABRIZ, 2003, p.272).

Nesse contexto, a quem cabe dar os contornos do direito à vida nas situações limítrofes apresentas pelas ciências biológicas? A quem cabe a decisão político-moral sobre a vida constitucionalmente protegida e o início dessa proteção?

$\mathrm{Na}$ busca por respostas, deve-se considerar o atual contexto brasileiro, no qual o Legislativo democraticamente eleito para representar a vontade popular passa por uma crise de 
legitimidade, enquanto o Judiciário expande seus poderes na regulação social, produzindo uma jurisprudência cada vez mais ativista, o que se deve em grande parte ao modelo híbrido de jurisdição constitucional adotado em 1988, um dos mais abrangentes do mundo (MENDES,2005).

O presente artigo tem por objetivo enfrentar essas questões utilizando a Arguição de Descumprimento de Preceitos Fundamentais n54 como estudo de caso, no qual, à luz das teorias da interpretação constitucional, analisaremos as tensões entre o Poder Judiciário e o Legislativo tendo em vista que a autorização da interrupção da gravidez nos casos de anencefalia fetal através da técnica da interpretação conforme a Constituição se refletiu diretamente na regulamentação do direito à vida, tema que se encontra em discussão através de projetos de lei em tramitação no Congresso Nacional, buscando no direito comparado elementos para a compreensão e solução da problemática apresentada.

\section{VIDA E ABORTO NA LEGISLAÇÃO BRASILEIRA}

A Convenção Americana sobre Direitos Humanos, conhecida como Pacto de São José da Costa Rica (OEA, 1969), ratificada pelo Brasil em 1992 com status supralegal, determina em seu art. $4^{\circ}$ que o respeito à vida é um direito de todos, do qual ninguém pode ser privado arbitrariamente, desde o momento da concepção.

O Código Civil brasileiro (BRASIL, 2002) afirma estarem assegurados os direitos do nascituro desde a concepção, entretanto não atribui a condição de pessoa ao ser humano concebido mas ainda não nascido.

Tornando ainda mais evidente a imprecisão jurídica, soma-se a ausência de requisitos legais para provar o nascimento com vida, o que fica a cargo das condutas médicas que investigam a respiração autônoma do indivíduo após o parto ${ }^{3}$, de modo que é a funcionalidade do sistema respiratório que atesta a vida extrauterina na maioria dos casos.

Cabe aqui destacar que embora tenha a mesma natureza fenomênica, a prova da morte recebeu maiores contornos jurídicos, tanto pelo Código Civil (que regula o fim da existência da

\footnotetext{
${ }^{3}$ As modificações internas no corpo do bebê geradas pela respiração oferecem aos peritos condições de um diagnóstico de vida extrauterina independente. Tais constatações são produzidas através das Docimásias Pulmonares, entre as quais a mais simples e mais comum é a Docimásia Hidrostática de Galeno. Para maiores informações ver: http://www.estudodirecionado.com/2013/01/docimasias-pulmonares.html. Acesso em 30 de julho de 2016.
} 
pessoa natural a partir de seu art. $6^{\circ}$ ), quanto pela Lei $n^{\circ} 9.434 / 97$, que exige o diagnóstico prévio de morte encefálica para autorizar a retirada de órgãos para fins de transplante.

No âmbito penal, a proteção da vida tanto extra quanto intrauterina está regulada entre os crimes contra a pessoa, definidos no Título I da parte especial do Código, elencando no capítulo dos crimes contra a vida o crime de Aborto, tipificado nos arts. 124 a 128 daquele diploma. A conduta incriminada consiste na interrupção da gravidez, feita pela gestante ou por terceiro, com ou sem o seu consentimento, havendo a previsão de duas cláusulas especiais de exclusão da ilicitude, que autorizam o aborto praticado por médico nas hipóteses descritas nos incisos I e II do art. 128 do CP.

O chamado "Aborto Legal" contempla duas modalidades: o "aborto necessário" e o "aborto sentimental". O primeiro pode ser praticado para salvar a vida da mãe, desde que a interrupção da gravidez seja a única alternativa terapêutica viável, independentemente da anuência da gestante, enquanto o segundo é autorizado quando a gravidez resultou de estupro, exigindo-se a concordância da mulher ou de seu representante legal (no caso de incapaz).

Desse modo, uma nova incongruência surge no sistema de regulamentação da vida no Direito brasileiro, pois ao contrário da legislação civil, o sujeito passivo do crime de aborto, isto é, o feto, é declarado pelo Direito Penal como sujeito de direitos, atribuindo-se à vida intrauterina a mesma tutela da vida extrauterina.

\section{A ADPF 54 E OS LIMITES DA INTERPRETAÇÃO CONFORME}

Em 17 de junho de 2004 a Confederação Nacional dos Trabalhadores da Saúde CNTS propôs Arguição de Descumprimento de Preceito Fundamental perante o Supremo Tribunal Federal, distribuída sob o número 54.

A ação girava em torno da alegada violação aos preceitos fundamentais da dignidade da pessoa humana, da legalidade, da liberdade, da autonomia da vontade e do direito à saúde da mulher, representados pela criminalização da antecipação terapêutica do parto de fetos anencefálicos com fulcro nos artigos 124, 126 e 128 do Código Penal.

A anencefalia é definida pela literatura médica (BEHRMAN; KLIEGMAN, 2002) como uma má-formação congênita, originada por uma falha na formação do tubo neural durante a gestação, em razão do que o feto não apresenta os hemisférios cerebrais completos, 
não havendo o fechamento da calota craniana. Segundo CNTS, essa patologia inviabiliza a vida extrauterina e por conseguinte a antecipação terapêutica do parto nessas hipóteses não tipificaria o crime de aborto, para o qual seria necessário a existência de um feto com a potencialidade de chegar a ser pessoa.

A ADPF 54 foi julgada por maioria de votos, oito anos após ter sido proposta, constando no inteiro teor do acórdão 433 páginas e a seguinte ementa:

ESTADO - LAICIDADE. O Brasil é uma república laica, surgindo absolutamente
neutro quanto às religiões. Considerações. FETO ANENCÉFALO -
INTERRUPÇÃO DA GRAVIDEZ - MULHER - LIBERDADE SEXUAL E
REPRODUTIVA - SAÚDE - DIGNIDADE - AUTODETERMINAÇÃO -
DIREITOS FUNDAMENTAIS - CRIME - INEXISTENCIA. Mostra-se
inconstitucional interpretação de a interrupção da gravidez de feto anencéfalo ser
conduta tipificada nos artigos 124, 126 e 128, incisos I e II, do Código Penal
(BRASIL, STF, 2012)

Essa interpretação do crime de aborto em conformidade com a Constituição alterou substancialmente a legislação penal, haja vista que a proteção da vida intrauterina passou a estar vinculada à sua viabilidade extrauterina, dando novos contornos à regulamentação do direito à vida.

Ressalte-se aqui que o presente trabalho não se propõe a discutir ou valorar o mérito da ADPF 54, nem se aprofundar nas questões relacionadas à legalização do aborto e aos direitos fundamentais da mulher, mas tão somente problematizar as consequências jurídicas na perspectiva da legitimidade das decisões político-morais tomadas pelo STF em sede de controle de constitucionalidade, notadamente através da técnica da interpretação conforme a Constituição.

Dito isto, passaremos agora a duas análises necessárias ao nosso objetivo: inicialmente faremos considerações acerca da interpretação conforme a Constituição e em seguida analisaremos a sua utilização pelo Supremo Tribunal Federal no julgamento da ADPF 54.

\subsection{Dimensões da interpretação conforme}

A interpretação conforme a Constituição tem ganhado cada vez mais espaço na jurisdição constitucional, sendo comumente utilizada como instrumento hábil à efetivação de direitos e garantias fundamentais via Poder Judiciário. Este movimento, engendrado pelo constitucionalismo moderno, forjado na normatividade do texto constitucional, isto é, na ideia 
de que os dispositivos constitucionais são cogentes e reclamam aplicabilidade imediata, afasta o caráter meramente programático de certos direitos previstos constitucionalmente, como bem ilustra o questionamento feito por Bobbio (2004, p.37):

\begin{abstract}
O campo dos direitos do homem - ou, mais precisamente, das normas que declaram, reconhecem, definem, atribuem direitos ao homem - aparece, certamente, como aquele onde é maior a defasagem entre a posição da norma e sua efetiva aplicação [...] Será que já nos perguntamos alguma vez que normas são essas que não ordenam, proíbem ou permitem hic et nunc, mas ordenam, proíbem e permitem num futuro indefinido e sem um prazo de carência claramente delimitado? E, sobretudo, já nos perguntamos que direitos são esses que tais normas definem? Um direito cujo reconhecimento e cuja efetiva proteção são adiados sine die, além de confiados à vontade de sujeitos cuja obrigação de executar o 'programa' é apenas uma obrigação moral ou, no máximo, política, pode ainda ser chamado corretamente de 'direito'?
\end{abstract}

Em relação à interpretação, não se pode afirmar que um determinado preceito legal possua um sentindo unívoco e absoluto, mas sim o contrário, que o significado de um texto normativo tende a se mostrar variável de acordo com o contexto social, histórico e jurídico (STRECK, 2000, p.239) no qual se encontra, exigindo constante trabalho exegético de readequação às mudanças socioculturais.

A conformidade com a Constituição apresenta-se então como um eficiente instrumento de interpretação normativa, promovendo o ajustamento da lei à decisão política fundamental, tendo como escopo o postulado da supremacia constitucional (KELSEN, 2003) e o princípio da conservação das normas jurídicas - derivado, a seu turno, da presunção de constitucionalidade das leis (LARENZ, 1997).

Note-se assim que tal mecanismo não se destina a interpretar a Constituição propriamente dita, mas a legislação infraconstitucional, como leciona Paulo Bonavides:

[...] em rigor, não se trata de um princípio de interpretação da Constituição, mas de um princípio de interpretação da lei ordinária de acordo com a Constituição. [...] Em suma, o método é relevante para o controle da constitucionalidade das leis e seu emprego dentro de razoáveis limites representa, em face dos demais instrumentos interpretativos, uma das mais seguras alternativas de que pode dispor o aparelho judicial para evitar a declaração de nulidade das leis. Por via de semelhante princípio, adotado sem excesso, o ato interpretativo não desprestigia a função legislativa nem tampouco enfraquece a magistratura nos poderes de conhecer e interpretar a lei pelo ângulo de sua constitucionalidade (2009, p.524)

Desse modo, sendo o ato de interpretar a possibilidade de obtenção de sentidos diversos, cabe ao intérprete atribuir à norma preferencialmente aquele que melhor se adeque aos princípios da Constituição, sem que seja necessário declarar a nulidade da lei (LARENZ, 1997; HESSE, 1998). 
Entretanto, mesmo preferível à nulidade, a utilização dessa técnica de interpretação deve guardar observância a certos limites, como alerta Karl Larenz:

\begin{abstract}
A interpretação conforme a Constituição, se quer continuar a ser interpretação, não pode ultrapassar os limites que resultam do sentido literal possível e do contexto significativo da lei. O Tribunal Constitucional Federal tem dito repetidamente que uma interpretação conforme à Constituição não é possível «em face do claro teor literal» da disposição. E tão pouco deve a interpretação conforme à Constituição deixar de atender ao escopo da lei. (1997, p.481)
\end{abstract}

Dito de outra forma, para o autor, com a finalidade de conformar a lei à ordem normativa constitucional, o intérprete não pode conferir-lhe um conteúdo material diverso ou uma nova consequência jurídica que dela não se derivasse originalmente, salvo nos casos em que o legislador tenha previsto um efeito mais amplo do que o tolerado pela Constituição, quando estaria o Tribunal autorizado a restringi-lo, preservando tudo o que fosse compatível com o sistema (1997, p.841).

No mesmo sentido é a lição de Canotilho:

[...] o aplicador de uma norma não pode contrariar a letra e o sentido dessa norma através de uma interpretação conforme a Constituição, mesmo que através desta interpretação consiga uma concordância entre a norma infraconstitucional e as normas constitucionais. (1999, p. 1151)

Dessa forma, a interpretação conforme a Constituição só é cabível diante de evidentes possibilidades de múltiplas significações, quando houver espaço para que o intérprete pondere a respeito dos sentidos aplicáveis à norma e não em qualquer ocasião com o fim de salvar um dispositivo a qualquer custo, alterando inclusive a própria literalidade do texto.

Por outro lado, o exercício interpretativo é tarefa produtiva, que embora possa utilizarse de elementos metodológicos históricos e teleológicos, não se destina a desvelar a vontade do legislador ou a "verdade" da lei, mas ao contrário, é ele que acaba por atribuir um sentido à norma (STRECK, 2002, p.449).

Sendo assim, qual o sentido constitucional dado pelo Supremo Tribunal Federal ao direito à vida no julgamento da ADPF 54? Qual o alcance da tutela constitucional que ali fora atribuída? E ainda, em que medida pode o Tribunal Constitucional legitimamente dar sentidos ao ordenamento jurídico? 


\subsection{Os argumentos judiciais da interpretação conforme na ADPF 54}

Segundo Cláudia Roesler (2016, p.83), as práticas argumentativas incidem diretamente na "construção e na reconstrução dos direitos". Dessa forma, a fim de compreender os efeitos gerados pelo julgamento da ADPF 54 sobre a regulamentação do direito à vida, faz-se necessário analisar os argumentos utilizados pelo STF para dar interpretação conforme a Constituição aos artigos 124, 126 e 128 do Código Penal.

A autora analisa que o padrão argumentativo utilizado na formulação e apresentação das decisões pelo STF através dos votos individuais dos ministros trazem uma variação tão grande de pontos e fontes, que dificulta a percepção de quais foram as razões de decidir, cuja consequência não é o efetivo debate sobre as questões, mas uma superposição de posições, resultando em uma ementa que

Realizada normalmente pelo relator ou pelo julgador que liderou a maioria, não raramente representa apenas os fundamentos da sua opinião e não incorpora de modo compreensível e visível o exposto pelos demais que, não tão raramente, concordam quanto à decisão, mas não quanto aos seus fundamentos. $(2016$, p.84)

No caso da Arguição de Descumprimento de Preceito Fundamental no 54, distribuída à relatoria do Ministro Marco Aurélio de Melo, a ação foi julgada procedente por maioria de votos, declarando-se inconstitucional a interpretação de que a interrupção da gravidez em caso de fetos anencéfalos configura o crime previsto nos arts. 124 e 126 do CP.

Votaram pelo deferimento do pedido os Ministros Marco Aurélio, Luiz Fux, Rosa Weber, Joaquim Barbosa, Carlos Britto, Cármen Lúcia e Celso de Melo, cujas razões apresentadas seguiam o mesmo entendimento do Ministro relator, e ainda o Ministro Gilmar Mendes, cuja argumentação divergia dos demais quanto à fundamentação, embora também favorável ao pleito. Foram contrários à Ação os Ministros Cesar Peluso e Ricardo Lewandowski. O Ministro Dias Toffoli se deu por impedido por ter participado do processo na qualidade de Advogado Geral da União.

Não pretendemos tecer minuciosas digressões sobre os argumentos apontadas nos votos dos Ministros. Entretanto importa-nos visitar os fundamentos apontados pelo Supremo Tribunal Federal, uma vez que eles permitem uma interpretação bastante afastada da literalidade do Código Penal, cujo efeito prático é a regulamentação da vida intrauterina no ordenamento jurídico. 
Iniciando pelos votos vencidos, as ponderações tecidas pelo Ministros Cezar Peluso enfrentaram a questão sob a perspectiva do nascituro enquanto titular do direito à vida, aduzindo que a interrupção da gravidez de fetos anencéfalos se adequa às condutas típicas dos aludidos artigos 124 e 126 do Código Penal em razão da existência de vida intrauterina, objeto da tutela jurídico-normativa, independentemente de eventuais deformidades que lhe possam acometer e diminuir a expectativa de vida extrauterina.

Já o voto divergente do Ministro Ricardo Lewandowski não tratou diretamente do direito à vida, e sim sobre os limites da interpretação conforme a Constituição para a autorizar intervenções nesse direito, asseverando que à Corte Suprema caberia agir com parcimônia a fim de não usurpar os poderes do Legislativo, considerando a clareza dos dispositivos do Código Penal. Para o Ministro, a literal autorização do aborto apenas em casos de gravidez resultante de estupro ou que implique em perigo para a vida da mãe, representa um limite à possibilidade de interpretação conforme a Constituição, de modo que a pretensão da ADPF 54 levaria o STF, a pretexto de interpretação constitucional da lei, a elaborar uma norma penal, o que lhe foge às competências constitucionais.

Sendo assim, caberia exclusivamente ao Congresso Nacional a competência para inserir no texto normativo uma nova hipótese de "aborto legal" de viés eugênico, nos casos de interrupção de gravidez de fetos anencéfalos, destacando a existência de projetos de lei sobre essa temática em trâmite nas casas legislativas.

Passando aos votos pela procedência, destacamos as razões apontadas pelo Ministro Gilmar Mendes, que apresentou posicionamento distinto dos demais Ministros, reconhecendo o nascituro como titular da tutela constitucional da vida, ponderando a inexistência de consenso social a respeito da vida e dignidade humana no feto anencefálico, entendendo, por outro lado, como necessária a interpretação que autoriza o aborto nessas hipóteses, para garantir atualização evolutiva da legislação, diante do surgimento de novo contexto fático-jurídico, distinto daquele que instituiu o Código Penal.

Os demais Ministros apontaram razões muito próximas às do voto do relator, razão pela qual nos ateremos à sua premissa fundamental: a viabilidade da existência extrauterina 


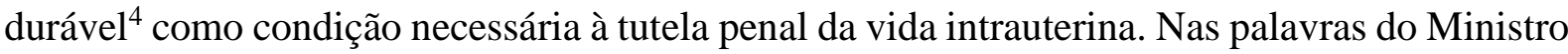
Marco Aurélio:

[...] o feto anencéfalo, mesmo que biologicamente vivo, porque feito de células e tecidos vivos, é juridicamente morto, não gozando de proteção jurídica e, acrescento, principalmente de proteção jurídico-penal. Nesse contexto, a interrupção da gestação de feto anencefálico não configura crime contra a vida - revela-se conduta atípica. [...] este Supremo Tribunal proclamou que a Constituição "quando se reporta a 'direitos da pessoa humana' e até dos 'direitos e garantias individuais' como cláusula pétrea está falando de direitos e garantias do indivíduo-pessoa, que se faz destinatário dos direitos fundamentais 'à vida, à liberdade, à igualdade, à segurança e à propriedade"”. [...] Ora, inexistindo potencialidade para tornar-se pessoa humana, não surge justificativa para a tutela jurídico-penal [...] (BRASIL, STF, 2012, p.55)

Para além da discussão sobre as condições próprias do feto anencefálico, depreendese do fragmento em destaque os seguintes contornos dados pelo STF ao direito à vida: o início da vida orgânica do fruto da concepção humana não se confunde com início da proteção jurídica da vida como um direito individual instituído pela Constituição, somente aplicável à vida extrauterina.

Consequentemente o nascituro não goza de proteção constitucional, e embora biologicamente vivo, seu "amparo" legal está condicionado à potencialidade de uma vida extrauterina mais ou menos prolongada. Consequentemente, nem toda vida intrauterina receberá tutela legal, mas tão somente a vida intrauterina considerada "viável".

Novamente não nos interessa perscrutar os aspectos morais e filosóficos do entendimento majoritário da decisão apreciada e nem chancelar uma ou outra tese em debate, mas tão somente questionar em que medida cabe à Suprema Corte regulamentar a vida intrauterina, estabelecendo os requisitos que a vida humana em gestação deve apresentar para merecer tutela penal, quando o legislador não fez tal restrição.

Sendo assim, passaremos ao debate acerca do papel do Poder Judiciário no constitucionalismo atual, em que a Corte Constitucional é chamada a solucionar demandas que pugnam pela efetividade de direitos fundamentais, e que lhe exigem mais do que a tradicional

\footnotetext{
${ }^{4}$ Utilizamos a expressão "durável" porque segundo documentos médicos que instruíram a ADPF 54, em muitos casos, fetos com anencefalia tiveram sobrevida por horas ou dias após o parto, apresentando batimentos cardíacos e respiração autônoma. Entretanto, por ser efêmero, esse período de existência não foi considerado como vida extrauterina.
} 
função de legislador negativo, tendo em vista a crise de legitimidade pela qual passa o poder Legislativo.

\section{O STF DE "LEGISLADOR NEGATIVO" A "LEGISLADOR POSITIVO"}

Ao estabelecer os requisitos para a tutela da vida intrauterina de modo a afastar a tipicidade do crime de aborto quando se tratar de feto anencéfalo, o Supremo Tribunal Federal está de fato interpretando o texto do código penal à luz da Constituição, ou está avançando, produzindo uma inovação no ordenamento jurídico acerca da tutela da vida, insculpindo na legislação uma nova excludente de ilicitude?

Em tese, uma decisão de ordem político-moral caberia ao Poder Legislativo, chancelado pelo voto popular para normatizar a vida social através de leis que reflitam os desejos da sociedade, princípio básico da democracia representativa, regulamentando legitimamente o alcance e os limites do Direito (BOBBIO, 2000, p.27), entre eles o direito à vida.

Todavia, a atuação do Legislativo brasileiro, sobretudo em temas polêmicos como os que envolvem o aborto e todas as suas nuances, padece de uma morosidade extrema, o que se prova pela tramitação dos projetos de Lei que versam sobre a matéria.

Passaram pelo Senado Federal até agora quatro Projetos de Lei (PLS) que visam a regulamentação do aborto nos casos de anencefalia ${ }^{5}$. Curiosamente, dois deles, já arquivados, foram propostos no ano de 2004, mesmo ano em que foi proposta a ADPF 54. São os PLS's 184 e 227 , este arquivado no ano de 2011 e aquele retirado pelo autor no mesmo ano de sua propositura.

Os outros dois projetos, PLS 50, do ano de 2011 e PLS 287 de 2012, preveem respectivamente a descriminalização e a criminalização da interrupção da gravidez em razão da anencefalia fetal, encontrando-se ambos sob análise da Comissão de Constituição e Justiça.

\footnotetext{
${ }^{5}$ Para maiores informações:

http://www25.senado.leg.br/web/atividade/materias?p_p_id=materia_WAR_atividadeportlet\&p_p_lifecycle=0\& _materia_WAR_atividadeportlet_tipo=PLS\&_materia_WAR_atividadeportlet_ano=\&_materia_WAR_atividade portlet_numero=\&_materia_WAR_atividadeportlet_palavraChave $=$ anencefalia\&_materia_WAR_atividadeportle t_autor=\&_materia_WAR_atividadeportlet_p=1 < acesso em 27 de julho de 2016>
} 
O primeiro, de autoria do Senador Mozarildo Cavalcanti, propõe a inserção de um inciso III ao artigo 128 do Código Penal a fim de incluir entre as cláusulas especiais de exclusão da ilicitude a interrupção da gravidez nos casos de anencefalia fetal. De acordo com a proposta, o diagnóstico deve ser realizado por três médicos que não pertençam à equipe responsável pelo procedimento.

O segundo, proposto pela Senadora Maria do Carmo Alves, tem por objetivo criminalizar a conduta do aborto em razão do diagnóstico de anencefalia fetal, acrescendo ao Código Penal os artigos 128-A, com pena de detenção de um a três anos para a mulher que interromper a própria gestação ou consentir que outrem o faça; $128-\mathrm{B}$, com pena de reclusão um a quatro anos para o terceiro que o fizer com o consentimento da gestante; e art. 128-C, com pena de reclusão de três a seis anos caso a interrupção da gravidez ocorra sem a anuência da gestante.

Ambos os projetos, em trâmite há mais de quatro anos, encontram-se ainda longe de chegar ao termo de seu processo legislativo. Enquanto isso, diante do silêncio normativo, no "mundo real", estabelecem-se questões sociais cada vez mais complexas, desdobrando-se em problemas concretos que envolvem o direito à vida, à saúde e a dignidade da pessoa humana.

Em um tal cenário é que se pode observar incontestavelmente o fenômeno da “judicialização", isto é, a decisão de controvérsias políticas e sociais de grande repercussão, não pelas instâncias legislativas tradicionais e sim pela via do Judiciário.

A produção normativa do Supremo Tribunal Federal surge como consequência dessa judicialização e apresenta-se como alternativa inerente ao cumprimento da função irrenunciável de Guardião da Constituição, que num constitucionalismo que lhe atribui força normativa imediata, exige uma atuação proativa do Judiciário a fim de garantir a efetividade de direitos fundamentais e sua aplicabilidade concreta.

Luís Roberto Barroso (2008) aponta três fatores diretamente responsáveis pela judicialização no Brasil: a abertura democrática, que proporcionou o exercício da cidadania e o fortalecimento de instituições como o Ministério Público e as Defensorias Públicas; a constitucionalização de diretrizes políticas e sociais; e finalmente um amplo sistema de controle de constitucionalidade, que obriga a manifestação da Corte Constitucional uma vez preenchidas as condições de admissibilidade (no caso do controle abstrato). 
Entretanto, leciona o autor, que a judicialização, por si só, não impõe um ativismo do Judiciário no campo de atuação dos outros Poderes, o que tende a acontecer apenas “[...] em situações de retração do Poder Legislativo, de um certo descolamento entre a classe política e a sociedade civil, impedindo que as demandas sociais sejam atendidas de maneira efetiva" $(2008$, p.6)

No mesmo sentido Cynara Mariano (2009, p.149) comenta que o ativismo judicial não foi a causa da "timidez" do parlamento brasileiro, mas o contrário, a maior inserção judicial na esfera legislativa tornou-se possível em razão do desvio funcional do legislativo, causado pela preponderância das "lutas partidárias pela continuidade do poder" em detrimento dos debates democráticos com vistas à efetivação de direitos que interessam ao povo.

Seria então possível afirmar que na salvaguarda dos direitos fundamentais o Supremo Tribunal Federal estaria autorizado a legislar quando o Congresso Nacional se esquivar deste exercício?

Segundo Gilmar Mendes (1999), não se pode dissociar normatividade e jurisdição constitucional, porque ao afastar alternativas normativas em controle de constitucionalidade, o STF atua também como "legislador positivo" à medida que, por via direta ou transversa, indica a norma admitida ou tolerada.

Entretanto, para juristas como Lenio Streck (2002), qualquer tentativa de acrescentar conteúdos ao texto em exame com o intuito de adequá-lo aos preceitos constitucionais, viola a separação dos poderes. Um tal modelo de "justiça constitucional" que transforma o Judiciário em "legislador positivo" invade a competência do Legislativo, minando os fundamentos do Estado Democrático de Direito.

Contudo não se pode negar que a decisão proferida pelo STF em sede de controle de constitucionalidade atendeu à demanda social por efetividade de direitos fundamentais, resolvendo uma lacuna deixada pelo parlamento, e diga-se, sem solução legislativa até os dias atuais, o que só corrobora a crise de representatividade e credibilidade pela qual passam as instâncias legislativas nacionais.

Observe-se que no caso da ADPF n ${ }^{\circ 54}$, o STF regulamentou a tutela constitucional da vida, restringindo-a ao ser humano já nascido, limitando a proteção infraconstitucional apenas à vida intrauterina considerada viável, premissa sobre a qual foi instituída, na prática, uma nova hipótese autorizadora do aborto, que por ora restringe-se aos casos de anencefalia, mas que 
brevemente poderá ser suscitada para outros casos de doenças ou má formação fetal que também inviabilizem a vida extrauterina, similares à anencefalia.

Entretanto, tal normatização judicial poderia prevalecer, caso os legítimos representantes da vontade popular (KANT, 2005, p.224), entre as distintas alternativas de uma sociedade pluralista decidissem através do processo político majoritário conceder a tutela penal da vida intrauterina independentemente de sua viabilidade, conforme prevê o PLS 287 de 2012 ?

Numa tentativa de responder à questão, sem a pretensão de esgotar o debate, recorremos novamente ao magistério de Luís Roberto Barroso (2008, p.18):

Os riscos para a legitimidade democrática, em razão de os membros do Poder Judiciário não serem eleitos, se atenuam na medida em que juízes e tribunais se atenham à aplicação da Constituição e das leis. Não atuam eles por vontade política própria, mas como representantes indiretos da vontade popular. É certo que diante de cláusulas constitucionais abertas, vagas ou fluidas - como dignidade da pessoa humana, eficiência ou impacto ambiental -, o poder criativo do intérprete judicial se expande a um nível quase normativo. Porém, havendo manifestação do legislador, existindo lei válida votada pelo Congresso concretizando uma norma constitucional ou dispondo sobre matéria de sua competência, deve o juiz acatá-la e aplicá-la. Ou seja: dentre diferentes possibilidades razoáveis de interpretar a Constituição, as escolhas do legislador devem prevalecer, por ser ele quem detém o batismo do voto popular.

Dito de outro modo, tendo o Legislativo a prerrogativa de assumir uma posição a respeito das questões de grande relevo moral e político, a concretização de direitos fundamentais através da lei afastaria o ativismo judicial, que nesses casos constituiria uma ameaça às bases do Estado Democrático de Direito, haja vista que a própria guarda da Constituição deve estar pautada nos valores ali encerrados, entre eles o princípio da separação dos Poderes.

Cabe aqui a valiosa ponderação de Cynara Mariano (2009, p.150) acerca do necessário movimento de reaproximação entre a classe política e os anseios da sociedade civil, com o consequente resgate da funcionalidade do Poder Legislativo:

[...] o próprio legislativo precisa recuperar sua dignidade, evitando que as lutas partidárias pela ocupação dos espaços políticos e pela reeleição sobreponham-se ao exercício da função legislativa propriamente dita e aos interesses do povo. Disposições legais ou constitucionais específicas garantindo ou negando o exercício de direitos sensíveis, como o direito de aborto ou os direitos dos homossexuais, por exemplo, provavelmente não remediariam as divisões existentes quanto a essas questões na sociedade, mas elas indubitavelmente afastariam o sentimento de usurpação da vontade popular quando regulamentações dessa natureza ocorrem no âmbito de sentenças judiciais. 
Faz-se necessário neste ponto analisar, pela via do direito comparado, como outros Estados Democráticos têm resolvido a questão do início da tutela constitucional da vida humana e suas implicações.

\section{A REGULAMENTAÇÃO DO INÍCIO DA TUTELA DA VIDA HUMANA NO DIREITO COMPARADO}

A regulamentação do início da proteção constitucional da vida como direito fundamental no direito estrangeiro está diretamente relacionada à legalização do aborto, e assim como no Brasil, é um tema sempre polêmico.

Segundo dados da Organização das Nações Unidas (2009), mais da metade dos países membros autorizam o aborto com base em pelo menos 01 dos seguintes fundamentos: (a) salvar a vida de uma mulher; (b) preservar a saúde física da mulher; (c) preservar a saúde mental da mulher; (d) em caso de estupro ou incesto; (e) por malformação fetal; (f) por razões económicas ou sociais; e (g) a pedido da gestante.

Com o objetivo de compreender como foi enfrentada legal e judicialmente no direito comparado a questão da tutela da vida e seus limites, passaremos a uma breve análise do processo de regulamentação do aborto na Itália e na Alemanha.

No ano de 1975 a Corte Constitucional italiana decidiu pela inconstitucionalidade parcial do art. 546 do Código Penal, que criminalizava o aborto sem prever a possibilidade de autorização para que o procedimento fosse realizado nos casos de risco à saúde da mulher. Em resposta à decisão judicial, em 1978 o parlamento editou a Lei 194, prevendo entre as possibilidades de aborto legal, além dos casos de risco para a saúde física e mental da gestante, também a autorização para o aborto em razão de circunstancias que envolvam a concepção, como o estupro; a detecção anomalia fetal, ou pelo comprometimento socioeconômico causado à vida da mulher (SARMENTO, 2005).

Essa lei determinou que antes da realização do aborto deve haver um diálogo entre a gestante e as autoridades a fim de buscar possíveis soluções para evitar a interrupção da gravidez, que só poderá ser realizada após 07 dias contados da solicitação, tendo por objetivo permitir à mulher uma maior reflexão.

A Corte Constitucional italiana foi chamada a se manifestar sobre o tema ainda em duas ocasiões: na primeira reconheceu que a previsão de condutas despenalizadoras pelo novo 
dispositivo legal pertencia exclusivamente à competência do Poder Legislativo, deixando de conhecer as suscitadas inconstitucionalidades, e na segunda, já em 1997, quando julgou inconstitucional a proposta de referendo que objetivava a eliminação de toda regulamentação do aborto nos primeiro 90 dias de gestação, por entende-la incompatível com a proteção constitucional da vida. (Sarmento, 2005)

No caso da Alemanha, o Tribunal Constitucional proferiu duas grandes decisões a respeito do aborto. A primeira delas, em 1975 conhecida como Aborto I, que julgou inconstitucional a autorização do aborto a pedido da gestante nas doze primeiras semanas de gestação, quando o Tribunal reconheceu o feto como um ser em desenvolvimento, dotado do direito à vida e de dignidade, que preponderam sobre a privacidade da mulher, salvo em hipóteses excepcionais. Em consequência deste julgamento, no ano seguinte foi novamente regulamentada a criminalização do aborto na Alemanha, com previsão de outras circunstâncias despenalizadoras, entre elas o aborto em razão de má formação fetal. (SARMENTO, 2005)

A decisão conhecida como Aborto II datada de 1993 ocorreu em virtude da alteração legislativa decorrente da unificação entre Alemanha Oriental e Alemanha Ocidental, que autorizou o aborto nos três primeiros meses da gravidez. Novamente o Tribunal declarou inconstitucional a lei, reconhecendo, entretanto, que a proteção do nascituro, considerado um ser humano em desenvolvimento, não precisaria se dar necessariamente pela via repressiva do Direito Penal. A consequência desse julgamento foi a edição de novo diploma legal em 1995, que além das hipóteses de aborto previstas na legislação anterior, descriminalizava o aborto nas 12 primeiras semanas de gestação, mas visando à proteção do feto, exigia a submissão da gestante a um serviço de aconselhamento para que mantivesse a gestação.

Verifica-se nos casos em análise, que tanto a Corte Constitucional Italiana, quando a corte Alemã reconheceram a existência de vida intrauterina e a supremacia de sua proteção constitucional em face dos direitos à liberdade de escolha e privacidade da gestante, cabendo entretanto, ao Legislativo, a decisão acerca das medidas para a garantia de sua proteção, bem como, considerando que não se trata de um direito absoluto, regulamentar as hipóteses despenalizadoras. 


\section{CONCLUSÃO}

O início da vida humana é uma questão que ainda suscita debates acalorados em vários campos do saber e principalmente na seara jurídica, haja vista que o legislador constituinte decidiu por bem silenciar a respeito do início da proteção da vida enquanto direito fundamental, cujas escolhas políticas pertinentes ao seu regramento maior ficaram a cargo do legislador ordinário, que o fez de modo incipiente.

Tal situação se torna mais problemática em razão dos avanços da biociência que podem ameaçar direitos fundamentais, aos quais o Judiciário é chamado a dar efetiva proteção, obrigando-o à manifestação acerca de questões político-morais.

É nesse contexto que o STF, utilizando-se da interpretação conforme a Constituição, declarou inconstitucional a interpretação da interrupção da gravidez de feto anencéfalo como conduta tipificada nos artigos 124, 126 e 128, incisos I e II, do Código Penal.

Concordaram os Ministros, por maioria de votos, com o argumento de que o nascituro ainda não goza da proteção constitucional à vida e que a tutela infraconstitucional que lhe cabe alcança somente os casos em que houver viabilidade de existência extrauterina.

Sem pretender analisar a correção política, ética e filosófica dessa decisão judicial, percebemos que a interpretação constitucional dada no caso em estudo é um reflexo da posição assumida pelo STF diante da crise do Legislativo. Desse modo, no intuito de atender a interesses sociais da mais alta relevância, ultrapassa os limites impostos à técnica da interpretação conforme a Constituição, estabelecendo um requisito para a tutela da vida intrauterina e uma descriminante não previstos pelo Pacto de São José da Costa Rica e nem pela legislação penal.

A transcendência das atribuições da Corte Constitucional afeta diretamente o processo majoritário de concretização do direito à vida em trâmite atualmente no Legislativo. Entretanto, impossível não reconhecer que tal postura supre a inércia daquele Poder, que protela os debates sobre tais questões polêmicas, tanto para evitar o desgaste público das imagens de seus membros, quanto pela maior importância dada a questões de outras naturezas, por vezes duvidosas.

$\mathrm{Na}$ tarefa assumida, encontramos um acirrado debate doutrinário acerca dos limites da interpretação constitucional, judicialização e ativismo judicial no Estado Democrático de Direito, no qual defensores e detratores de uma postura judicial mais ativa para dar efetividade 
aos direitos constitucionalmente previstos, apontam, além da Constituição, a lei, como limite à atividade interpretativa dos juízes e Tribunais.

Isto nos leva a concluir que o controle da legitimidade de atuação do Supremo Tribunal Federal depende de uma atividade "prévia" do Poder Legislativo: a edição de leis que promovam a concretização dos direitos fundamentais, tarefa para a qual foi constituído pela vontade popular.

Todavia a omissão das funções parlamentares, a inércia nos debates sobre temas constitucionais polêmicos ou a regulamentação precária de seus conteúdos revela o descompasso entre os interesses sociais e a atividade legislativa.

A lacuna deixada pelo Poder Legislativo, em franco descrédito social, leva as demandas populares ao Judiciário, que diante da indeterminação legal tem ampliado seu espaço de atuação. Acreditando-se que o contrário se constituiria também verdadeiro: precisas determinações legais e reduzidas ambiguidades não permitiriam, ou pelo menos tornariam mais difíceis a inovação judicial.

No campo do direito comparado, observa-se que em compasso com a jurisdição constitucional nas decisões de controle de constitucionalidade sobre o aborto, cujo pano de fundo é em última análise a regulamentação do direito à vida, tanto o parlamento italiano quanto o alemão trataram de concretizar os direitos fundamentais através de leis consonantes às respectivas declarações de inconstitucionalidade.

Desta forma, Judiciário e Legislativo devem agir conjuntamente na efetivação de direitos fundamentais, tendo em vista que a imposição de força normativa à Constituição aplicase a todos os poderes, fazendo-se necessário que o parlamento desempenhe essa função de modo primordial, a fim de redimensionar os espaços de atuação da Corte Constitucional e permitir o controle de suas decisões. 


\section{REFERÊNCIAS}

ALEXY, Robert. Teoria dos Direitos Fundamentais. Tradução de Virgílio Afonso da Silva da 5 ed. São Paulo: Malheiros, 2008

BARROSO, Luis Roberto. Judicialização, Ativismo Judicial e Legitimidade Democrática. p. 4. Disponível em:

http://www.conjur.com.br/2008-dez-22/judicializacao_ativismo_legitimidade_democratica Acesso em 25 de julho de 2016

BEHRMAN, Richard E.; KLIEGMAN, Robert M. Tratado de Pediatria. Ed. Guanabara Koogen, 2002.

BOBBIO, Norberto Bobbio. A era dos Direitos. Tradução Carlos Nelson Coutinho. Rio de Janeiro: Elsevier, 2004.

BOBBIO, Norberto. Direito e Estado no pensamento de Emanuel Kant. São Paulo: Mandarim, 2000

BONAVIDES, Paulo. Curso de Direito Constitucional. 24a ed. São Paulo: Malheiros, 2009.

BRASIL. Decreto-lei 2.840, de 07 de dezembro de 1940

. Lei 10.406, de 10 de janeiro de 2002

. Supremo Tribunal Federal. ADPF-54. Disponível

em:http://www.osconstitucionalistas.com.br/wp-content/uploads/acordao-ADPF-54.pdf Acesso em 05 de maio de 2016.

CANOTILHO, José Joaquim Gomes. Direito Constitucional e Teoria da Constituição. $3^{\text {a }}$ ed. Coimbra : Livraria Almedina. 1999.

DELMANTO, Celso. Código Penal Comentado. $6^{\text {a }}$ ed. Rio de Janeiro: Renovar, 2002

DWORKIN, Ronald, Domínio da vida. Aborto, eutanásia e liberdades individuais. São Paulo: Martins Fontes, 2003

FABRIZ, Daury César. Bioética e Direitos Fundamentais: a bioconstituição como paradigma ao biodireito. Belo Horizonte: Mandamentos, 2003

HESSE, Konrad. Elementos de Direito Constitucional da República Federal da Alemanha. Porto Alegre: Sérgio A. Fabris, 1998

KANT, Immanuel. Metafísica dos costumes. Tradução: José Lamego. Lisboa: Fundação Calouste Gulbekian, 2005

KELSEN, Hans. Teoria Pura do Direito. $3^{\text {a }}$ ed. São Paulo: Revista dos Tribunais, 2003 
LARENZ, Karl. Metodologia da Ciência do Direito. Tradução José Lamego. Lisboa: Fundação Calouste Gulbenkian, 19997

MARIANO, Cynara Monteiro. Legitimidade do Direito e do Poder Judiciário na

Democracia Brasileira: O restabelecimento da primazia do poder constituinte, do poder legislativo e de um positivismo ético na teoria constitucional. 2009. Tese (Doutorado em Direito Constitucional). 182f. Universidade de Fortaleza. UNIFOR. Fortaleza. 2019.

MENDES, Gilmar Ferreira. Jurisdição constitucional. São Paulo: Saraiva, 2005 . Gilmar. Teoria da Legislação e Controle de Constitucionalidade: Algumas

Notas. Revista Jurídica Virtual - Brasília, vol. 1, n. 1, maio 1999

ORGANIZAÇÃO DOS ESTADOS AMERICANOS. Convenção Americana de Direitos Humanos. 1969

ORGANIZAÇÃO DAS NAÇÕES UNIDAS, Department of Economic and Social Affairs, Population Division, World Population Policies 2009. United Nations publication, Sales No. E.09.XIII.14. Disponível

em:www.un.org/esa/population/publications/wpp2009/Publication_complete.pdf Acesso em 29 de maio de 2016

ROESLER, Cláudia Rosane. Entre o Paroxismo de Razões e Razão Nenhuma: Paradoxos de uma Prática Jurídica. Revista de Direito da Universidade de Brasília, Brasília, v. 2, n. 1, p.79-95, 2016.

Disponível em:http://revistadireito.unb.br/index.php/revistadireito/article/view/104/104

Acesso em 29 de maio de 2016

SARMENTO, Daniel. Legalização do Aborto e Constituição. Revista de Direito Administrativo, Rio de Janeiro, p.43-82, Abril/Junho, 2005. Disponível em: http://bibliotecadigital.fgv.br/ojs/index.php/rda/article/view/43619/44696. Acesso em 22 de junho de 2016.

STRECK, Lenio Luiz. Hermenêutica Jurídica e(m) Crise. 2000. Porto Alegre : Livraria do Advogado.

Lenio Luiz. Jurisdição Constitucional e Hermenêutica. Uma Nova Crítica do Direito. Porto Alegre : Livraria do Advogado. 2002, p. 449 